\title{
ANALISIS METODE BAYESIAN PADA SISTEM ANTREAN RAWAT JALAN DI RSUP Dr. KARIADI DENGAN DISTRIBUSI SAMPEL POISSON DAN GEOMETRIK
}

\author{
Nur Azizah ${ }^{1}$, Sugito $^{2}$, Hasbi Yasin ${ }^{3}$ \\ 1,2,3 Departemen Statistika, Fakultas Sains dan Matematika, Universitas Diponegoro \\ e-mail: anur82654@gmail.com
}

\begin{abstract}
Hospital service facilities cannot be separated from queuing events. Queues are an unavoidable part of life, but they can be minimized with a good system. The purpose of this study was to find out how the queuing system at Dr. Kariadi. Bayesian method is used to combine previous research and this research in order to obtain new information. The sample distribution and prior distribution obtained from previous studies are combined with the sample likelihood function to obtain a posterior distribution. After calculating the posterior distribution, it was found that the queuing model in the outpatient installation at Dr. Kariadi Semarang is $(\mathrm{G} / \mathrm{G} / \mathrm{c})$ : $(\mathrm{GD} / \infty / \infty)$ where each polyclinic has met steady state conditions and the level of busyness is greater than the unemployment rate so that the queuing system at Dr. Kariadi is categorized as good, except in internal medicine poly.
\end{abstract}

Keywords: RSUP Dr. Kariadi, Queue, Bayesian, Steady State, Posterior

\section{PENDAHULUAN}

Upaya negara untuk menyediakan fasilitas kesehatan salah satunya dengan mendirikan rumah sakit di berbagai daerah, sehingga salah satu elemen dasar dalam menumbuhkan ketahanan nasional dapat terpenuhi. Tujuan didirikannya rumah sakit adalah untuk memberikan pelayanan kesehatan yang mampu meningkatkan mutu kesehatan masyarakat yang merata dan terjangkau di seluruh lapisan masyarakat. Oleh karena itu, sebuah rumah sakit diharapkan dapat memberikan pelayanan terbaik yang mampu memberikan rasa nyaman dan bisa menumbuhkan kepercayaan masyarakat sehingga bersedia menempatkan kepercayaan mereka terhadap rumah sakit tersebut dengan memakai jasa kesehatan yang pihak rumah sakit tawarkan.

Fasilitas pelayanan rumah sakit tidak bisa lepas dari peristiwa antrean. Salah satu permasalahan yang terjadi pada fasilitas pelayanan umum adalah yang terlihat pada instalasi rawat jalan yaitu lamanya proses menunggu pada instalasi rawat jalan di RSUP Dr. Kariadi. Secara teoritis peristiwa mengantre akan terjadi apabila jumlah pasien yang berkunjung lebih banyak dibandingkan dengan pasien terlayani. Hal tersebut mengakibatkan pasien tidak terlayani secara maksimal oleh pihak rumah sakit karena jumlah waktu yang terbatas. Tujuan mempelajari pengoperasian sebuah sarana pelayanan adalah untuk memperoleh beberapa karakteristik yang mengukur kinerja sistem yang sedang dipelajari tersebut (Taha, 1996).

Pada penelitian sebelumnya oleh (Rachmawati, 2013) didapat gambaran yang tepat dan efisien pada sistem antrean dan ukuran kinerja sistem antrean pada instalasi rawat jalan di RSUP Dr. Kariadi Semarang. Metode Bayesian memberikan informasi baru yang dapat memperbaiki penelitian sebelumnya. Dalam pandangan Bayes, seseorang dapat memberikan kepercayaan awal (prior believe) terhadap suatu parameter karena adanya asumsi bahwa parameter merupakan suatu variabel acak (Bolstad, 2007). Dengan menggunakan Teorema 
Bayes, informasi awal yang dinyatakan dengan distribusi prior dan informasi sampel yang dinyatakan dengan fungsi likelihood dikombinasikan untuk membentuk distribusi posterior (Soejati, Z. dan Soebanar, 1988).Distribusi posterior didapat dari perhitungan fungsi likelihood dan distribusi prior.

\section{TINJAUAN PUSTAKA}

\section{A. Profil Rumah Sakit Umum Pusat (RSUP) Dr. Kariadi}

RSUP Dr. Kariadi merupakan rumah sakit terbesar dan merupakan rumah sakit rujukan yang berlokasi di daerah Semarang, Jawa Tengah dengan alamat lengkap di Jalan Dr. Sutomo Nomor 16 Semarang. RSUP Dr. Kariadi merupakan rumah sakit tipe A dimana sarana dan prasarana yang tersedia di RSUP Dr. Kariadi sudah memenuhi standar yang telah ditetapkan oleh menteri dan mempunyai fasilitas serta kemampuan pelayanan medik spesialistik luas..

\section{B. Deskripsi Antrean}

Fenomena menunggu merupakan hasil dari keacakan dalam operasional pelayanan fasilitas. Secara umum, kedatangan customer dan waktu pelayanannya tidak diketahui untuk waktu selanjutnya. Sebaliknya fasilitas operasional dapat diatur sehingga dapat mengurangi antrian (Aminudin, 2005). Proses antrean (queueing process) adalah suatu proses yang berhubungan dengan kedatanagan pelanggan serta fasilitas pelanggan pada suatu fasilitas pelayanan, menunggu dalam baris antrean jika belum dapat dilayani, dilayani dan akhirnya meninggalkan fasilitas tersebut sesudah dilayani.

\subsection{Ukuran Steady State}

Steady state merupakan kondisi sewaktu sifat-sifat sistem tidak berubah dengan berjalannya waktu (konstan). Menurut Taha (1996), misalnya $\lambda$ adalah rata-rata kedatangan pelanggan ke tempat pelayanan per satuan waktu, $\mu$ adalah ratarata pelanggan yang telah dilayani per satuan waktu, dan c merupakan banyaknya fasilitas tempat pelayanan (server), maka $\rho$ didefinisikan sebagai perbandingan antara rata-rata pelanggan yang datang $(\lambda)$ dengan rata-rata pelanggan yang telah dilayani per satuan waktu $(\mu)$, atau dapat dituliskan sebagai berikut:

\subsection{Proses Poisson}

$$
\rho=\frac{\lambda}{c \mu}
$$

Menurut Praptono (1986) proses Poisson adalah proses cacah yang mempunyai batasan tertentu diantaranya $\mathrm{N}(\mathrm{t})$ mengikuti distribusi Poisson dengan rata-rata $\lambda \mathrm{t}$ dimana $\lambda$ suatu konstanta. Beberapa asumsi untuk proses poisson diantaranya:

1. Independen

$\mathrm{N}(\mathrm{t})$ independen terhadap banyaknya kejadian yang terjadi didalam selang waktu yang lalu. Artinya $\mathrm{N}(\mathrm{t})$ tak tergantung pada kejadian sebelumnya.

2. Homogenitas dalam waktu

Homogenitas dalam waktu $\operatorname{Pn}(\mathrm{t})$ hanya tergantung pada panjang $t$ atau panjang selang waktu, tetapi tidak tergantung dimana selang waktu berada.

3. Regularitas 
Regularitas yaitu dalam suatu interval kecil $(\Delta \mathrm{t})$, probabilitas bahwa tepat satu kejadian terjadi adalah $\lambda(\Delta \mathrm{t})+\mathrm{o}(\Delta \mathrm{t})$ dan probabilitas bahwa banyaknya kejadian terjadi lebih dari sekali adalah $\mathrm{o}(\Delta \mathrm{t})$ dalam interval $\Delta \mathrm{t}$, sedangkan simbol $\mathrm{o}(\Delta \mathrm{t})$ digunakan untuk menyatakan fungsi $\Delta \mathrm{t}$ yang mendekati 0 lebih cepat dari $\Delta$ t sendiri mendekati 0 , artinya

$f(\Delta t)$ disebut $\mathrm{o}(\Delta \mathrm{t}) \leftrightarrow \lim _{\Delta \mathrm{t} \rightarrow 0} \frac{f(\Delta \mathrm{t})}{\Delta \mathrm{t}}=0$

\subsection{Uji Kolmogorov-Smirnov}

Menurut Daniel (1989), asumsi dalam uji Kolmogorov Smirnov adalah data terdiri atas hasil pengamatan bebas $\mathrm{X} 1, \mathrm{X} 2, \ldots, \mathrm{Xi}, \quad$ yang merupakan sebuah sampel acak berukuran i dari suatu fungsi distribusi yang belum diketahui dan dinyatakan dengan F0(xi).

Adapun langkah-langkah uji Kolmogorov Smirnov sebagai berikut:

a. Menentukan Hipotesis

$\mathrm{H}_{0}$ : Distribusi sampel mengikuti distribusi yang ditetapkan

$\mathrm{H}_{1}$ : Distribusi sampel tidak mengikuti distribusi yang ditetapkan

b. Menentukan Taraf Signifikansi

Taraf signifikansi yang digunakan adalah $\alpha=5 \%$

c. Statistik Uji

$\mathrm{D}=\max \left(\max \left(\left|S(x i)-F_{0}(x i)\right|,\left|S(x i-1)-F_{0}(x i)\right|\right)\right.$

$1 \leq \mathrm{i} \leq \mathrm{r}$

dengan:

S(xi) : fungsi peluang kumulatif yang dihitung dari data sampel

$\mathrm{F}_{0}(\mathrm{xi})$ : fungsi distribusi yang dihipotesiskan (fungsi peluang kumulatif)

$\mathrm{r} \quad$ : banyaknya nilai x yang berbeda

d. Kriteria Uji

Tolak H0 jika pada taraf signifikansi $\alpha$ jika nilai $\mathrm{D}>$ nilai $\mathrm{D}^{*}\left(\frac{\alpha}{2}\right)$ atau jika nilai sig < nilai $\alpha$.

$\mathrm{D} *\left(\frac{\alpha}{2}\right)$ adalah nilai kritis yang diperoleh dari Tabel Kolmogorov-Smirnov untuk uji dua sisi.

2.6. Distribusi Gamma

Menurut Bain dan Engelhardt (1992), sebuah variabel random kontinu X berdistribusi gamma dengan parameter $k>0$ dan $\theta>0$ jika memiliki fungsi kepadatan peluang sebagai berikut :

$$
f(x ; \theta, \mathrm{k})=\frac{1}{\theta^{k} \Gamma(k)} y^{k-1} e^{\frac{k}{\theta}}, \mathrm{y}>0
$$

Notasi pada keadaan tersebut, yaitu :

$\mathrm{X} \sim \operatorname{Gamma}(\theta, \mathrm{k})$

2.7. Distribusi Geometrik

Menurut Bain dan Engelhardt (1992), sebuah variable random diskrit X, jika memiliki fungsi kepadatan peluang sebagai berikut :

$$
\mathrm{g}(\mathrm{x} ; \mathrm{p})=\mathrm{pq}^{\mathrm{x}-1} \quad \mathrm{x}=1,2,3
$$

Notasi pada keadaan tersebut, yaitu :

$$
\mathrm{X} \sim \operatorname{GEO}(p)
$$




\subsection{Distribusi Beta}

Menurut Spiegel, Schiller dan Srinivasan (2004), suatu variable acak dikatakan memiliki distribusi Beta dengan parameter $\alpha$ dan $b$, jika fungsi kepadatannya adalah

$$
f(x)=\left\{\begin{array}{lc}
\frac{1}{B(\alpha, \mathrm{b})} x^{\alpha-1}(1-x)^{b-1} & 0<x<1 \\
0 & \text { yang lain }
\end{array}\right.
$$

dimana $B(\alpha, b)$ merupakan fungsi Beta yang didefinisikan sebagai

$$
\mathrm{B}(\alpha, \mathrm{b})=\int_{0}^{1} x^{\alpha-1}(1-x)^{b-1} d x \quad a>0, b>0
$$

Fungsi Beta dihubungkan dengan fungsi Gamma:

$$
\mathrm{B}(\alpha, \mathrm{b})=\frac{\Gamma(\alpha) \Gamma(\mathrm{b})}{\Gamma(a+b)}
$$

Sehingga distribusi Beta juga dapat didefinisikan oleh fungsi kepadatan :

$$
f(x)=\left\{\begin{array}{lr}
\frac{\Gamma(\alpha) \Gamma(\mathrm{b})}{\Gamma(a+b)} x^{\alpha-1}(1-x)^{b-1} & 0<x<1 \\
0 & \text { yang lain }
\end{array}\right.
$$

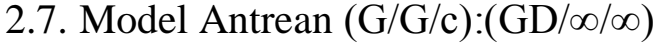

Menurut Gross dan Harris (dalam, Sihotang, E., 2019) model antrean

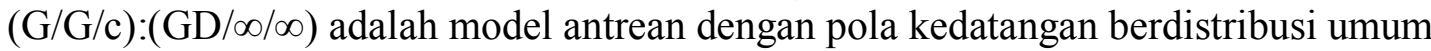
(general) dan pola pelayanan berdistribusi umum (general) dengan jumlah fasilitas pelayanan sebanyak c, c = 1, 2, 3, ... Disiplin antrean yang digunakan pada model ini adalah umum yaitu FCFS (First Come First Service), kapasitas maksimum yang diperbolehkan dalam sistem adalah tak hingga dan memiliki sumber pemanggilan takhingga. Untuk penghitungan jumlah pelanggan yang diperkirakan dalam antrean (Lq)

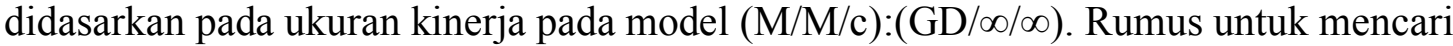
ukuran-ukuran kinerja pada model $(\mathrm{G} / \mathrm{G} / \mathrm{c}):(\mathrm{GD} / \infty / \infty)$ adalah :

dengan :

$$
L_{q}=\left(\frac{\rho r^{c}}{c !(1-\rho)^{2}}\right) P_{0} \frac{\mu^{2} v(t)+v\left(t^{\prime}\right) \lambda^{2}}{2}
$$

$$
\begin{aligned}
& \mathrm{v}(\mathrm{t})=\left(1 /\left(\mu^{2}\right)\right)^{2} \\
& \mathrm{v}\left(\mathrm{t}^{\prime}\right)=\left(1 /\left(\lambda^{2}\right)\right) \\
& \mathrm{Ls}=\mathrm{Lq}+\mathrm{r} \\
& \mathrm{Wq}=\frac{L q}{\lambda} \\
& \mathrm{Ws}=\mathrm{Wq}+\frac{1}{\mu}
\end{aligned}
$$

\subsection{Metode Bayesian}

Menurut Box dan Tiao (1973), diketahui bahwa $x^{\prime}=(x 1, \ldots, x n)$ adalah vektor dari pengamatan sebanyak $\mathrm{n}$ dengan distribusi probabilitas $\mathrm{p}(\mathrm{x} \mid \lambda)$ adalah probabilitas bersyarat $\mathrm{y}$ jika diketahui nilai dari $\mathrm{k}$ parameter $\lambda$ adalah $\lambda^{\prime}=(\lambda 1, \ldots, \lambda \mathrm{k})$. Diketahui bahwa $\lambda$ memiliki distribusi probabilitasnya sendiri yaitu $\mathrm{p}(\lambda)$, dengan

$$
\begin{aligned}
& p(x \mid \lambda) p(\lambda)=p(\lambda \mid x) p(x)=p(x, \lambda) \\
& \text { sehingga didapatkan persamaan : } \\
& p(\lambda \mid x)=\frac{p(x \mid \lambda) p(\lambda)}{p(x)}
\end{aligned}
$$

2.9. Distribusi Prior 
Box dan Tiao (dalam, Nadhifah.L, 2012) menjelaskan bahwa distribusi prior dikelompokkan menjadi dua kelompok berdasarkan bentuk fungsi likelihood-nya, yaitu :

1. Berkaitan dengan bentuk distribusi hasil identifikasi pola datanya dapat dibedakan menjadi:

a. Distribusi prior sekawan (conjugate), mengacu pada acuan analisis model terutama dalam pembentukan fungsi likelihoodnya sehingga dalam penentuan prior sekawan selalu dipikirkan mengenai penentuan pola distribusi prior yang mempunyai bentuk sekawan dengan fungsi densitas peluang pembangun likelihood-nya.

b. Distribusi prior tidak sekawan (non-conjugate), apabila pemberian bentuk distribusi prior yang tidak sekawan dengan bentuk hasil identifikasi dari datanya.

2. Berkaitan dengan penentuan masing-masing parameter pada pola distribusi prior tersebut, dapat dibedakan menjadi dua bentuk yang berbeda, yaitu:

a. Distribusi prior informatif mengacu pada pemberian parameter dari distribusi prior yang telah dipilih baik distribusi prior sekawan atau tidak, pemberian nilai parameter pada distribusi prior ini didasarkan pada informasi data yang diperoleh.

b. Distribusi prior non-informatif, pemilihannya tidak didasarkan pada data yang ada atau distribusi prior yang tidak mengandung informasi tentang parameter $\lambda$.

2.10. Metode Jeffrey's

Menurut Berger (1980) salah satu bentuk pendekatan dari prior non-informatif adalah dengan menggunakan metode Jeffrey. Metode ini menyatakan bahwa distribusi prior $(\lambda)$ merupakan akar kuadrat dari informasi Fisher yang dinyatakan dalam:

$$
\begin{aligned}
& f(\lambda)=[I(\lambda)]^{1 / 2} \\
& I(\lambda)=-E_{0}\left[\frac{\partial^{2} \ln L(\lambda)}{\partial \lambda^{2}}\right]
\end{aligned}
$$

dimana :

$(\lambda)$ : Distribusi prior

$E_{0}$ : Nilai harapan

$(\lambda)$ : Informasi Fisher

\subsection{Fungsi Likelihood}

Informasi yang diperoleh mengenai fungsi kepekatan peluang dari data sampel disebut fungsi likelihood. Menurut Bain dan Engelhardt (1992), fungsi likelihood adalah fungsi densitas bersama dari $\mathrm{n}$ variabel random $\mathrm{Y} 1, \mathrm{Y} 2, \ldots$, Yn dan dinyatakan dalam bentuk $f(y 1$, $y 2, \ldots, y n ; \lambda)$. Jika $y 1, y 2, \ldots, y n$ ditetapkan, maka fungsi likelihood adalah fungsi dari parameter $\lambda$ dan dinotasikan dengan $L(\lambda)$. Jika Y1, Y2,..,Yn menyatakan suatu sampel random dari $f(y \mid \lambda)$, maka:

$$
\begin{aligned}
(\lambda) & =f(y 1 \mid \lambda) f(y 2 \mid \lambda) \ldots f(y n \mid \lambda) \\
& =\prod_{i=1}^{n} \mathrm{f}(\mathrm{yi} \mid \lambda)
\end{aligned}
$$

\subsection{Distribusi Posterior}

Menurut Soejati Subanar (1988), Ditribusi posterior adalah fungsi densitas bersyarat $\lambda$ jika diketahui nilai observasi $\mathrm{x}$. Ini dapat dituliskan sebagai:

$$
\mathrm{f}(\lambda \mid \mathrm{x})=\frac{f(\lambda, x)}{f(x)}
$$


Fungsi densitas posterior untuk variable random kontinu dapat ditulis sebagai : $\mathrm{f}(\lambda \mid \mathrm{x})=\frac{f(\lambda) \mathrm{f}(\mathrm{x} \mid \lambda)}{\int_{-\infty}^{\infty} f(\lambda) \mathrm{f}(\mathrm{x} \mid \lambda) \mathrm{d} \lambda}$

\section{METODE PENELITIAN}

\subsection{Sumber Data dan Variabel Peneltian}

Pada penelitian ini data yang digunakan adalah data primer. Penelitian ini dilaksanakan di Instalasi Rawat Jalan, Unit Merpati RSUP Kariadi dengan waktu pelaksanaan tanggal 23 Februari - 8 Maret 2021. Variabel yang digunakan adalah data jumlah kedatangan dan pelayanan pasien yang dilayani pada poli saraf, poli penyakit dalam, poli CDC, poli anak dan poli kandungan di Unit Merpati RSUP Dr. Kariadi Semarang.

3.2. Langkah-langkah Analisis

Prosedur yang dilakukan dalam penelitian dan analisis data dijelaskan sebagai berikut :

1. Melakukan penelian secara langsung di RSUP Dr Kariadi Semarang. Peneliti mengamati waktu kedatangan pasien guna mendapatkan jumlah kedatangan tiap unit waktu $(\lambda)$, dan waktu pelayanan guna mendapatkan jumlah yang dilayani per unit waktu $(\mu)$, jumlah kedatangan dan pasien dan jumlah pasien terlayani.

2. Mendapatkan data jumlah kedatangan dan jumlah pelayanan dalam interval waktu yang ditentukan.

3. Pemeriksaan kondisi steady state pada data $\left(\rho=\frac{\lambda}{\mu}<1\right)$ dengan $\lambda$ sebagai rata-rata kedatangan pasien dan $\mu$ sebagai rata-rata pasien yang telah dilayani. Apabila data belum memenuhi kondisi steady state maka disarankan untuk melakukan penambahan jumlah pelayanan atau memepercepat waktu pelayanan.

4. Melakukan kecocokan uji distribusi poisson dengan menggunakan KolmogorovSmirnov dengan software R-Gui pada jumlah kedatangan dan pelayanan. Apabila hipotesis nol diterima maka data mengikuti distribusi poisson dan apabila hipotesis nol ditolak maka dilakukan kembali uji kecocokan distribusi lainnya.

5. Kemudian dilakukan uji kecocokan distribusi selain poisson, sesuai dengan distribusi yang paling tepat menggunakan software easy fit.

6. Setelah diketahui distribusi yang sesuai, kemudian menghitung distribusi posterior dengan menggunakan distribusi awal sebagai fungsi likelihood.

7. Menghitung distribusi posterior dengan menggunakan distribusi prior yang tersedia yaitu data antrian pelayanan rawat jalan RSUP Dr. Kariadi sebelumnya.

8. Menentukan model antrean yang sesuai.

9. Melakukan perhitungan dan analisis antrian untuk mendapatkan ukuran kinerja sistem antrian yaitu jumlah pelangganyang diperkirakan dalam antrian (Lq), jumlah pelanggan yang diperkirakan dalam sistem (Ls), waktu menunggu dalam antrian (Wq), dan waktu menunggu dalam sistem(Ws).

10. Membuat hasil dan pembahasan yang diperoleh dari kinerja sistem.

11. Mengambil kesimpulan mengenai sistem pelayanan di RSUP Dr. Kariadi Semarang secara keseluruhan.

\section{HASIL DAN PEMBAHASAN}

4.1. Ukuran Steady State

Berikut adalah tabel ukuran steady state untuk masing-masing poli: 
Tabel 1. Ukuran Steady State

\begin{tabular}{ccccc}
\hline Poli & Lambda & Miu & c & p \\
\hline Penyakit Dalam & 9,89 & 11,13 & 15 & 0,06 \\
Kandungan & 3,83 & 4,6 & 5 & 0,1667 \\
Anak & 6,58 & 6,58 & 10 & 0,1 \\
Saraf & 3,83 & 4,6 & 3 & 0,28 \\
CDC & 3,75 & 4,29 & 12 & 0,07 \\
\hline
\end{tabular}

Nilai p kurang dari 1 artinya bahwa keadaan ini memenuhi kondisi steady state.

\subsection{Uji Kecocokan Distribusi}

Uji Kecocokan distribusi yang digunakan pada penelitian ini adalah uji Kolmogorov Smirnov untuk mengetahui data jumlah kedatangan dan pelayanan berdistribusi poisson atau tidak.

Tabel 2. Uji Kolmogorov Smirnov Jumlah Kedatangan

\begin{tabular}{|c|c|c|c|c|c|}
\hline Poli & $\mathrm{D}$ & $\mathrm{D}^{*}(\alpha / 2)$ & Sig & Keputusan & Kesimpulan \\
\hline $\begin{array}{l}\text { Penyakit } \\
\text { Dalam }\end{array}$ & 0,25553 & 0,309 & 0,1904 & $\begin{array}{l}\mathrm{H}_{0} \\
\text { diterima }\end{array}$ & $\begin{array}{l}\text { Data berdistribusi } \\
\text { poisson }\end{array}$ \\
\hline Kandungan & 0,24469 & 0,375 & 0,4689 & $\begin{array}{l}\mathrm{H}_{0} \\
\text { diterima }\end{array}$ & $\begin{array}{l}\text { Data berdistribusi } \\
\text { poisson }\end{array}$ \\
\hline Anak & 0,32284 & 0,375 & 0,32284 & $\begin{array}{l}\mathrm{H}_{0} \\
\text { diterima }\end{array}$ & $\begin{array}{l}\text { Data berdistribusi } \\
\text { poisson }\end{array}$ \\
\hline Saraf & 0,24469 & 0,375 & 0,4689 & $\begin{array}{l}\mathrm{H}_{0} \\
\text { diterima }\end{array}$ & $\begin{array}{l}\text { Data berdistribusi } \\
\text { poisson }\end{array}$ \\
\hline CDC & 0,19788 & 0,409 & 0,558 & $\begin{array}{l}\mathrm{H}_{0} \\
\text { diterima }\end{array}$ & $\begin{array}{l}\text { Data berdistribusi } \\
\text { poisson }\end{array}$ \\
\hline
\end{tabular}

Tabel 3. Uji Kolmogorov Smirnov Jumlah Pelayanan

\begin{tabular}{|c|c|c|c|c|c|}
\hline Poli & $\mathrm{D}$ & $D^{*}(\alpha / 2)$ & Sig & Keputusan & Kesimpulan \\
\hline $\begin{array}{l}\text { Penyakit } \\
\text { Dalam }\end{array}$ & 0,34019 & 0,327 & 0,04298 & $\mathrm{H}_{0}$ ditolak & $\begin{array}{l}\text { Data tidak berdistribusi } \\
\text { poisson }\end{array}$ \\
\hline Kandungan & 0,31803 & 0,409 & 0,2639 & $\begin{array}{l}\mathrm{H}_{0} \\
\text { diterima }\end{array}$ & $\begin{array}{l}\text { Data berdistribusi } \\
\text { poisson }\end{array}$ \\
\hline Anak & 0,31577 & 0,327 & 0,1826 & $\begin{array}{l}\mathrm{H}_{0} \\
\text { diterima }\end{array}$ & $\begin{array}{l}\text { Data berdistribusi } \\
\text { poisson }\end{array}$ \\
\hline Saraf & 0,38576 & 0,409 & 0,102 & $\begin{array}{l}\mathrm{H}_{0} \\
\text { diterima }\end{array}$ & $\begin{array}{l}\text { Data berdistribusi } \\
\text { poisson }\end{array}$ \\
\hline $\mathrm{CDC}$ & 0,19788 & 0,409 & 0,558 & $\begin{array}{l}\mathrm{H}_{0} \\
\text { diterima }\end{array}$ & $\begin{array}{l}\text { Data berdistribusi } \\
\text { poisson }\end{array}$ \\
\hline
\end{tabular}

Data pelayanan poli penyakit dalam tidak berdistribusi poisson, sehingga dilakukan uji lanjutan untuk mengetahui distribusi yang sesuai menggunakan software easy fit.

Tabel 4. Uji Kolmogorov Smirno Data Pelayanan Poli Penyakit Dalam

\begin{tabular}{lcccll}
\hline \multicolumn{1}{c}{ Poli } & $\mathrm{D}$ & $\mathrm{D} *(\alpha / 2)$ & Sig & Keputusan & Kesimpulan \\
\hline $\begin{array}{l}\text { Penyakit } \\
\text { Dalam }\end{array}$ & 0,20032 & 0,32733 & 0,48135 & $\begin{array}{l}\mathrm{H}_{0} \\
\text { diterima }\end{array}$ & $\begin{array}{l}\text { Data berdistribusi } \\
\text { geometrik }\end{array}$ \\
\hline
\end{tabular}


Berdasarkan uji Kolmogorov Smirnov diperoleh kesimpulan bahwa jumlah pelayanan poli penyakit dalam berdistribusi geomterik.

\subsection{Model Antrean Bayesian}

\section{a. Prior}

Dengan menggunakan metode Jeffrey sebagai salah satu pendekatan untuk distribusi non-infotmatif prior diketahui sebagai berikut:

$$
\begin{aligned}
& f(x ; \lambda) \quad=\frac{e^{-\lambda} \lambda^{x}}{x !} \\
& \log f(\mathrm{x} ; \lambda)=\log \left(\frac{e^{-\lambda} \lambda^{x}}{x !}\right) \\
& \mathrm{I}(\lambda)=-\mathrm{E}_{\lambda}\left[-\frac{X}{\lambda^{2}}\right] \quad \mathrm{f}(\lambda) \quad=\sqrt{I(\lambda)} \\
& =\mathrm{x} \log \lambda-\log \mathrm{x} !-\lambda \\
& =\frac{1}{\lambda^{2}} \mathrm{E}_{\lambda}(\mathrm{x}) \\
& =\sqrt{\frac{1}{\lambda}} \\
& \frac{\partial \log f(x ; \lambda)}{\partial \lambda}=\frac{x}{\lambda}-1 \\
& =\frac{1}{\lambda^{2}}(\lambda) \\
& =\lambda^{-\frac{1}{2}} \\
& =\frac{1}{\lambda}
\end{aligned}
$$

Sehingga distribusi prior $\mathrm{f}(\mathrm{x} ; \lambda)=\lambda^{-\frac{1}{2}}$

b. Likelihood

\section{Likelihood Distribusi Poisson}

$\operatorname{Poisson}(\lambda), 0<\lambda, x=0,1, \ldots$

$$
\begin{gathered}
L(f(x ; \lambda))=\prod_{i=1}^{n} \frac{e^{-\lambda} \lambda^{x_{i}}}{x_{i} !} \\
=\frac{e^{-n \lambda} \lambda^{\Sigma_{i=1}^{n} x_{i}}}{\prod_{i=1}^{n} x_{i !}}
\end{gathered}
$$

\section{Likelihood Distribusi Geometrik}

Untuk $(\mathrm{x}=1,2,3, \ldots)$

$$
\begin{aligned}
f(x ; p) & =p(1-p)^{x-1} \\
L(f(x ; p)) & =\prod_{i=1}^{n} p(1-p)^{x_{i}-1}
\end{aligned}
$$

c. Distribusi Posterior

\section{Distribusi Prior Poisson dan Likelihood Poisson}

$$
\begin{aligned}
\mathrm{f}(\mathrm{x} ; \lambda) & =\mathrm{f}(\mathrm{x} \mid \lambda) x \mathrm{f}(\lambda) \\
\mathrm{f}(\lambda \mid \mathrm{x}) & =\frac{f(x ; \lambda)}{\int f(x ; \lambda)} \\
& =\frac{e^{-n \lambda} \lambda^{-\frac{1}{2}+\sum_{i=1}^{n} x_{i}}}{\prod_{i=1}^{n} x_{i !}} x \frac{\prod_{i=1}^{n} x_{i !}}{\Gamma\left(\frac{1}{2}+\sum_{i=1}^{n} x_{i}\right)\left(n^{-1}\right)^{\sum_{i=1}^{n} x_{i}+\frac{1}{2}}}
\end{aligned}
$$




$$
\begin{gathered}
=\frac{e^{-n \lambda} \lambda^{-\frac{1}{2}+\sum_{i=1}^{n} x_{i}}}{\Gamma\left(\frac{1}{2}+\sum_{i=1}^{n} x_{i}\right)\left(n^{-1}\right)^{\sum_{i=1}^{n} x_{i}+\frac{1}{2}}} \\
\sim \operatorname{Gamma}\left(\frac{1}{n}, \sum x+\frac{1}{2}\right)
\end{gathered}
$$

\section{Distribusi Prior Poisson dan Likelihood Gemoterik}

$$
\begin{aligned}
\mathrm{f}(\mathrm{x} ; \lambda) & =\mathrm{f}(\mathrm{x} \mid \lambda) x \mathrm{f}(\lambda) \\
\mathrm{f}(\lambda \mid \mathrm{x}) & =\frac{f(x ; \lambda)}{\int f(x ; \lambda)} \\
& =\frac{\frac{1}{\lambda^{1 / 2}} \prod_{i=1}^{n} \lambda(1-\lambda)^{x_{i}-1}}{\int_{-\infty}^{\infty} \frac{1}{\lambda^{1 / 2}} \prod_{i=1}^{n} \lambda(1-\lambda)^{x_{i}-1}} \\
& =\frac{\lambda^{n-1 / 2}(1-\lambda)^{\sum_{i=1}^{n} x_{i}-n}}{\int_{-\infty}^{\infty} \lambda^{n-1 / 2}(1-\lambda)^{\sum_{i=1}^{n} x_{i}-n}} \\
& =\frac{\Gamma\left(\sum_{i=1}^{n} x_{i}+3 / 2\right)}{\Gamma(n+1 / 2) \Gamma\left(\sum_{i=1}^{n} x_{i}-n+1\right)} \lambda^{n-1 / 2}(1-\lambda)^{\sum_{i=1}^{n} x_{i}-n}
\end{aligned}
$$

Sehingga diketahui $\lambda \mid x \operatorname{Beta}\left(n+\frac{1}{2} ; \sum_{i=1}^{n} x_{i}-n+1\right)$

\subsection{Model Antrean}

Berikut tabel model antrean untuk masing-masing poli:

Tabel 7. Model Antrean

\begin{tabular}{lccc}
\hline \multicolumn{1}{c}{ Poli } & $\begin{array}{c}\text { Distribusi } \\
\text { Kedatangan }\end{array}$ & $\begin{array}{c}\text { Distribusi } \\
\text { Pelayanan }\end{array}$ & Model \\
\hline Penyakit Dalam & Gamma & Beta & $(\mathrm{G} / \mathrm{G} / 15):(\mathrm{GD} / \infty / \infty)$ \\
Kandungan & Gamma & Gamma & $(\mathrm{G} / \mathrm{G} / 5):(\mathrm{GD} / \infty / \infty)$ \\
Anak & Gamma & Gamma & $(\mathrm{G} / \mathrm{G} / 10):(\mathrm{GD} / \infty / \infty)$ \\
Saraf & Gamma & Gamma & $(\mathrm{G} / \mathrm{G} / 3):(\mathrm{GD} / \infty / \infty)$ \\
CDC & Gamma & Gamma & $(\mathrm{G} / \mathrm{G} / 12):(\mathrm{GD} / \infty / \infty)$ \\
\hline
\end{tabular}

\subsection{Ukuran Kinerja Sistem}

Ukuran kinerja sistem antrean pada tiap-tiap poli yang didapatkan dari output GUI R sebagai berikut:

Tabel 8. Ukuran Kinerja Sistem

\begin{tabular}{llllll}
\hline No & Poli & Lq & Ls & Wq & Ws \\
\hline 1 & Penyakit Dalam & $1,692998 \times 10^{-46}$ & 0.01217902 & $2,865216 \times 10^{-47}$ & 0,002061166 \\
2 & Kandungan & $5,514655 \times 10^{-5}$ & 1,386687 & $4,501536 \times 10^{-6}$ & 0,1131933 \\
3 & Anak & 0,00165658 & 1,388288 & 0,0001352243 & 0,113324 \\
4 & Saraf & 0,0009318265 & 1,387563 & $5,704777 \times 10^{-5}$ & 0,08494866 \\
5 & CDC & $7,645839 \times 10^{-12}$ & 1,277464 & $4,814199 \times 10^{-13}$ & 0,08043545 \\
\hline
\end{tabular}


Berdasarkan tabel diperoleh jumlah pelanggan dalam antrean, jumlah pelanggan dalam sistem, waktu pelanggan dalam antrean, dan waktu pelanggan dalam sistem untuk masingmasing loket.

\section{KESIMPULAN}

Kesimpulan yang diperoleh dari hasil analisis dan pembahasan pada penelitian ini yaitu didapat distribusi posterior gamma dan beta dengan perkalian antara prior dan likelihood sampel, sistem pelayanan pada tiap-tiap poli di instalasi rawat jalan RSUP Dr. Kariadi

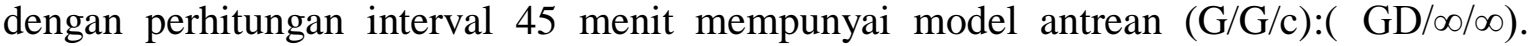
Kinerja sistem pelayanan di RSUP Dr. Kariadi dikatakan sudah baik berdasarkan perhitungan ukuran kinerja sistem dimana probabilitas pada masing-masing poli lebih besar daripada probabilitas menganggur, kecuali pada poli penyakit dalam.

\section{DAFTAR PUSTAKA}

Aminudin. 2005. Prinsip-Prinsip Riset Operasi. Jakarta: Erlangga.

Bain, L. J. dan Engelhardt, M. 1992. Introduction To Probability and Mathematical Statistics Second Edition. California: Duxburry Press.

Bolstad, W. 2007. Introduction to Bayesian Statistics Second Edition. (J. W. Sons, Ed.) America.

Box, G.E.P. dan Tiao, G.C. 1973. Bayesian Inference In Statistical Analysis. Philippines: Addision-Wesley Publishing Company.inc.

Daniel, W. W. 1989. Statistik Nonparametrik Terapan (Terjemahan). Jakarta: PT Gramedia.

Nadhifah.L. et al. 2012. Analisis Faktor-Faktor yang Mempengaruhi Bayi Berat Lahir Rendah dengan Model Regresi Logistik Biner Menggunakan Metode Bayes (Studi Kasus di Rumah Sakit Umum Daerah Kota Semarang). Jurnal Gaussian, 125-134.

Praptono. 1986. Pengantar Proses Stokhastik I. Jakarta: Karunika

Sihotang, E. et al. 2019. Analisis Antrean dan Kinerja Sistem Pelayanan Gardu Tol Otomatis Gerbang Tol Muktiharjo (Studi Kasus : Gardu Tol Otomatis Gerbang Tol Muktiharjo). Jurnal Gaussian, 106-116.

Soejati, Z. dan Soebanar. 1988. Inferensi Bayesian. Jakarta: Karunika Universitas Terbuka.

Spiegel, M.R, Schiller, J.J dan Srinivasan, R.A. 2013. Schaum's Outline of Probability Fourth Edition. New York: The McGraw-Hill Companies Inc.

Taha, H. A.1996. Riset Operasi : Jilid Dua. Jakarta: Binarupa Aksara. 